\title{
Portal Vein Thrombosis with Tropical Splenomegaly-A Rare Coincidental Finding
}

Nalini Bansal Gupta ${ }^{1 *}$, Manav Wadhawan ${ }^{2}$ and Varun Gupta ${ }^{3}$

${ }^{1}$ SRL Ltd, Fortis Escorts Heart Institute, Okhla Road, New Delhi, India

${ }^{2}$ Hepatology Fortis Escorts, New Delhi, India

${ }^{3}$ Hepatology, Fortis Hospital, Gurgaon, New Delhi, India

*Corresponding Author: Nalini Bansal Gupta, Senior Histopathologist, SRL Ltd, Fortis Escort Heart Institute Okhla, New Delhi, India, Tel: 9990370677; E-mail: drnalinibansal@yahoo.com

Received date: November 6, 2017; Accepted date: January 1, 2018; Published date: January 5, 2018

Copyright: $\odot 2017$ Gupta NB, et al. This is an open-access article distributed under the terms of the Creative Commons Attribution License, which permits unrestricted use, distribution, and reproduction in any medium, provided the original author and source are credited.

\begin{abstract}
Tropical splenomegaly syndrome has rarely been associated as a cause of portal hypertension in patients living in endemic malarial zone. TSS has however has never been reported to be associated with portal vein thrombosis.

We report a case of a 17 year old male who presented with features of portal hypertension and on radiological evaluation was found to have portal vein thrombus with cavernoma formation. Liver biopsy was performed for ruling out other pathologies and cirrhosis and was found to have hemozoin pigment along with features of inflow vascular pathology. We here in report first case of tropical splenomegaly with portal vein thrombosis.
\end{abstract}

Keywords Liver; Splenomegaly syndrome; Portal vein thrombosis; Cirrhosis; Vascular pathology

\section{Introduction}

Portal hypertension has long been described as a complication of tropical splenomegaly syndrome (TSS). However, occurrence of portal vein thrombosis (PVT) has never been described to be associated with TSS. Cases of PVT being misdiagnosed as TSS though have been described in literature. We herein report a case of a young male who presented with features of portal hypertension and on CT was found to have portal vein thrombus. On work up for same a liver biopsy was performed and there was evidence of malarial hemozoin pigment together with features of inflow vascular pathology.

\section{Case Report}

We report a case of a 17-year-old male resident of West Africa from Angola who presented with grade 3 oesophageal varices and abdominal mass. His CT Angio abdomen done revealed chronic intrahepatic portal vein thrombus with secondary dilation of portal vein system and collateral venous malformation. There was severe splenomegaly measuring $20 \times 17 \times 11 \mathrm{cms}$ with medial displacement of the left kidney. Patient also underwent banding once for Grade 3 oesophageal varices. His liver function test was normal with a bilirubin of $0.8 \mathrm{mg} / \mathrm{dl}$, SGOT/SGPT- 45 and $40 \mathrm{U} / \mathrm{L}$, alkaline phosphatase and Gamma GGT 85 and 65 U/L. His total protein and albumin was also normal. His complete blood count revealed $\mathrm{Hb}$ of $11.8 \mathrm{~g} / \mathrm{dl}$, low platelets of $25 \mathrm{cumm}^{3}$ with low total leucocyte count of $1.41 \mathrm{cumm}^{3}$. When we did a coagulation profile, his INR and aPTT were normal. Thrombocheck profile revealed normal protein $\mathrm{C}$ and $\mathrm{S}$, lupus anticoagulant, antithrombin activity, homocysteine, antiphospholipid antibodies and no JAK-2 mutation or Factor V leiden mutation.
To determine the cause of portal hypertension a liver biopsy was performed under USG guidance after transfusing platelets and bringing level above $50,000 \mathrm{cumm}^{3}$. The biopsy revealed 16 portal tracts with all the tracts showing presence of prominent pigment laden marcophages (Figure 1). The pigment was blackish brown in colour and was refractile on polarising light showing yellowish brown granular birefringes. The pigment did not stain with PAS, PAS-D stains (Figure 2). There was no maltese cross appearance formation. There was also presence of supernumery and herniating portal vein profiles indicating inflow vascular pathology (Figure 3). Hepatic lobules showed maintained architecture with focally presence of sinusoidal pigment within kupffer cells. There was no evidence of increased fibrosis or cirrhosis. There were no atrophic tracts indicating non cirrhotic portal fibrosis.

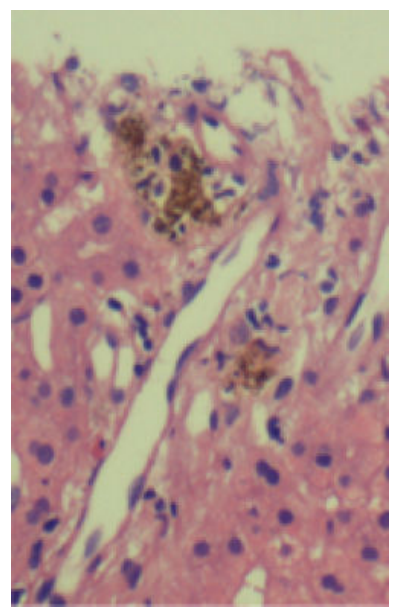

Figure 1: Showing presence of pigment within macrophages. 
Page 2 of 3

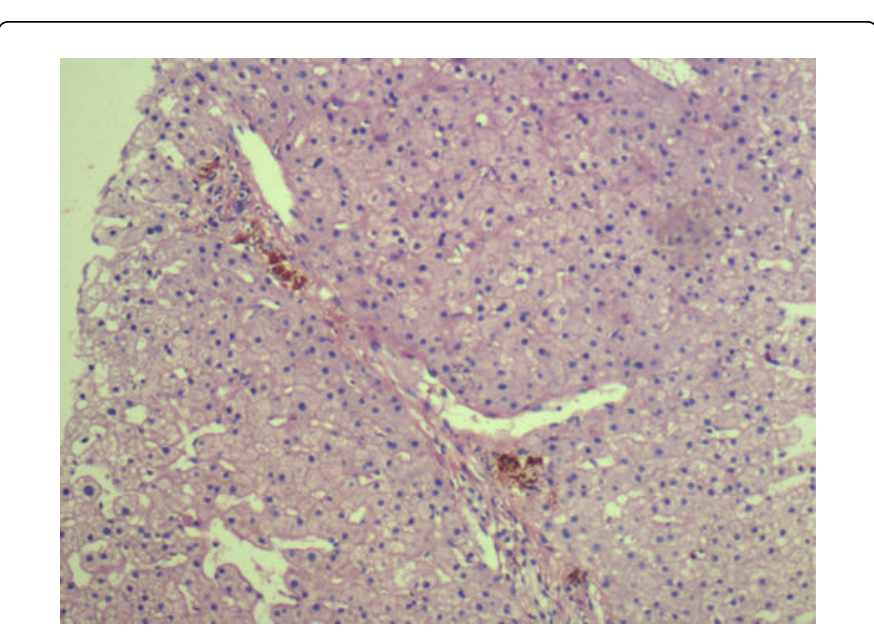

Figure 2: PAS D stain showing no staining within the pigment.

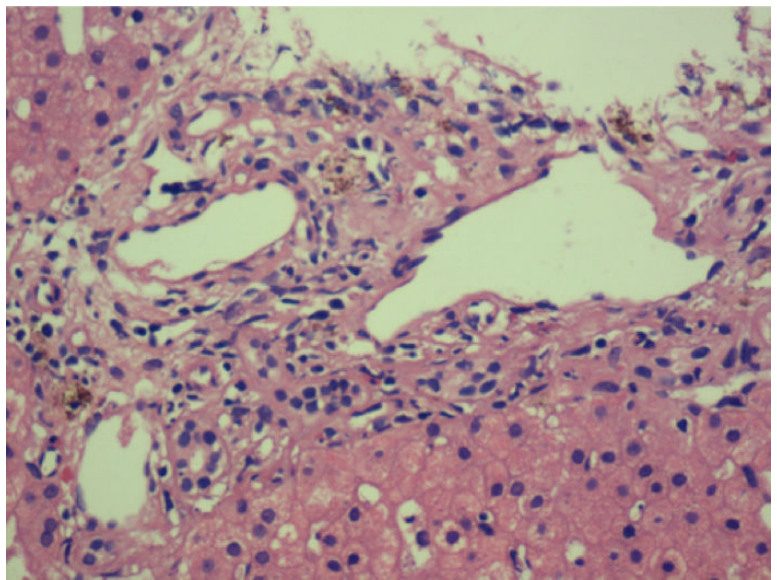

Figure 3: Showing supernumery herniating venous profiles within tracts.

On further elucidation of history and laboratory parameters, it was found that patient was a resident of endemic malarial zone. He had three brothers who had several episodes of malaria; however patient denied any history of fever. His IgG and IgM antibodies were elevated but no malarial antigen was detected in the blood.

Patient was finally diagnosed as a case of inflow vascular pathology along with presence of hemozoin pigment within the liver parenchyma. The portal hypertension was due to hyperdynamic circulation in splenic vein secondary to massive splenomegaly which got aggravated due to the development of portal thrombosis.

He was started on antimalarial therapy for 3 months. In order to relieve portal hypertension and reduce risk of variceal bleeding, he was operated for distal spleno-renal shunt with splecectomy. Post-surgery after 6 week patient is doing well with improved well-being and his pancytopenia has corrected.

\section{Discussion}

There exists some confusion in the nomenclature of PVT and EHPVO which are sometimes overlapping.

Portal vein thrombosis refers to the complete or partial obstruction of blood flow in the portal vein, due to the presence of a 'thrombus' in the vessel lumen. It can be intra-hepatic or extra-hepatic, and may also extend upstream to the splenic and/or the mesenteric veins [1].

Extra-Hepatic Portal Vein Obstruction refers to 'obstruction' of the extrahepatic portion of the portal vein with or without involvement of the intra-hepatic portal veins, and does not include isolated thrombosis of splenic vein or superior mesenteric vein.

Portal vein thrombosis (PVT) can occur as a complication of cirrhosis in $10-15 \%$ of the population secondary to increased hepatic resistance and obstruction to portal outflow. It can also occur as a tumour thrombus in patient who develops Hepatocellular carcinoma. PVT further leads to portal hypertension and secondary splenomegaly [2].

Extrahepatic portal vein obstruction (EHPVO) is found to be due to multiple etiological factors, most common of which includes umbilical sepsis during the neonatal period [3]. Others include deficiency of coagulation factors like protein $\mathrm{C}, \mathrm{S}$ factor $\mathrm{V}$ leiden mutation etc $[4,5]$.

PVT occurring due to tropical splenomegaly has never been described. It is essential to understand that pathogenesis of portal hypertension in cirrhosis and isolated massive splenomegaly is different. Pathophysiology of development of portal hypertension in TSS has been postulated to be due to increase in liver blood flow which leads to increase intrasplenic pressure and wedged hepatic venous pressures (WHVP). Secondly there is also increase in presinusoidal resistance. There is no occurrence of intrahepatic resistance in isolated massive splenomegaly (as in TSS) which can lead to microvascular thrombosis and PVT in patients, as it occurs in cirrhosis). However the exact pathogenesis, which has caused PVT in our patient, could not be elucidated.

There is a case report by Lee etal indicating that cases of PVT are misdiagnosed as Tropical Splenomegaly [6]. They reported a case of a 27 -year-old Indian female who was treated for malaria infection since 9 years of age due to splenomegaly. Later on further examination was found to have PVT with normal liver histology.

Tropical splenomegaly Syndrome (TSS) is also known as Hyperreactive Malarial Syndrome (HMS) is caused by repeated malarial infection in patients residing in zones endemic for malaria [7]. Most of these patients presents with abdominal pain due to massive splenomegaly. Splenomegaly is caused because of deposition of malarial antigen antibody immune complexes within the reticuloendothelial system. Splenomegaly leads to pancytopenia as was also seen in our case. There is repeated B cell activation by chronic malarial antigenemia leading to polyclonal $\mathrm{B}$ cell activation and release of IgM in these patients leading to high serum IgM levels.

India and Africa have been regarded as endemic zones for malaria. The incidence of malaria has been rising in Angola and our patient was also a resident from same area [8].

In our patient liver involvement was characterised by presence of hemozoin pigment within kupffer cells and macrophages within liver [9-11]. Presence of hemozoin pigments within macrophages along with history of patient from endemic malarial zone, and high immunoglobulins lead us to believe coexistence of TSS along with 
Citation: Gupta NB, Wadhawan M, Gupta V (2018) Portal Vein Thrombosis with Tropical Splenomegaly-A Rare Coincidental Finding. J Liver 7: 225. doi:104172/2167-0889.1000225

Page 3 of 3

portal vein thrombosis. Portal hypertension and PVT can occur even without any damage to the liver and sometimes is difficult to reach a final diagnosis. A diagnosis in this case was made only after histopathology study of the liver.

\section{References}

1. Kumar A, Sharma P, Arora A (2014) Review article: portal vein obstruction--epidemiology, pathogenesis, natural history, prognosis and treatment.Aliment Pharmacol Ther 41: 276-292.

2. Janssen HL, Wijnhoud A, Haagsma EB, van Uum SH, van Nieuwkerk $\mathrm{CM}$, et al. (2001) Extrahepatic portal vein thrombosis: Aetiology and determinants of survival Gut 49: 720-724.

3. Poddar U, Thapa BR, Rao KL, Singh K (2008) Etiological spectrum of esphageal varices due to portal hypertension in Indian children: is it different from the West? J Gastroenterol Hepatol 23: 1354-1357.

4. Poddar U, Thapa BR, Singh K (2003) Endoscopic sclerotherapy in children: experience with 257 cases of extrahepatic portal venous obstruction. Gastrointest Endosc 57: 683-686.
5. Dubuisson C, Boyer-Neumann C, Wolf M, Meyer D, Bernard O (1997) Protein $\mathrm{C}$, protein $\mathrm{S}$ and antithrombin III in children with portal vein obstruction. J Hepatol 27: 132-135.

6. Lee SM, Wong NW, Rathakrishnan V (1989) Are we missing portal vein thrombosis? Sing Med J 30: 388-389.

7. Raval N, Shah N, Vani SN (1991) Tropical splenomegaly syndrome, Indian J of Pediatrics 58: 679-681.

8. De Cock KM, Hodgen AN, Lucas SB, Jupp RA, Slavin B, et al. (1987) Chronic splenomegaly in Nairobi, Kenya. I. Epidemiology, malarial antibody and immunoglobulin levels. Trans R Soc Trop Med Hyg 81: 100-106.

9. Acharya S, Shukla S, Mahajan SN, Diwan SK, Chaudhary K (2010) Hyperreactive malarial syndrome with non-cirrhotic portal hypertension. Ann Trop Med Public Health 3: 75-77.

10. Williams R, Somers K, Hamilton PJS, Parsonson A (1996) Portal hypertension in tropical splenomegaly. Lancet 1:329-333.

11. Baheti R, Laddha P, Gehlot RS (2003) Liver Involvement in Falciparum Malaria-A Histo-pathological Analysis. J Indian Academy Clinical Med JIACM 4: 34-38. 